\title{
Collaborative research: Development of a manual on elasmobranch handling and release best practices in tropical tuna purse-seine fisheries
}

\author{
François Poisson ${ }^{\mathrm{a}, *}$, Bernard Séret ${ }^{\mathrm{b}}$, Anne-Lise Vernet ${ }^{\mathrm{c}}$, Michel Goujon ${ }^{\mathrm{c}}$, Laurent Dagorn ${ }^{\mathrm{d}}$ \\ a Institut Français de Recherche pour l'Exploitation de la Mer (Ifremer), UMR 212, Bd Jean Monnet, BP 171, \\ 34203 Sète Cedex, France \\ b Institut de Recherche pour le Développement (IRD), UMR 212, Muséum national d'Histoire naturelle, \\ Département Systématique et Evolution, CP 51, 55 rue Buffon, 75231 PARIS cedex 05, France \\ ${ }^{c}$ Orthongel, Nouvelle criée bureau 10- Ep 12729181 Concarneau cedex, France \\ d Institut de Recherche pour le Développement (IRD), UMR 212, Bd Jean Monnet, BP 171, 34203 Sète Cedex, \\ France
}

*: Corresponding author : François Poisson, Tel.: +33 499573245 ; fax: +33499573295 ;
email address : francois.poisson@ifremer.fr

\begin{abstract}
:
The reduction of by-catch mortality is an objective of the ecosystem approach to fisheries and a request made by consumers. Elasmobranchs, an important component of the French tropical tuna purse seine fishery by-catch, are currently thrown back into the sea. Fishers interact with various types of elasmobranchs that range widely in size, weight and shape, and could pose various degrees of danger to the crew. A diversity of discarding practices within the fleet were reported, some practices were considered suitable, others needed to be adapted and improved and others simply had to be banned. The majority of the crews were likely to improve their handling practices if they were presented with practical suggestions that were quick and easy. Combining scientific observations and empirical knowledge from skippers and crew, a manual, providing appropriate handling practices to ensure crew safety and increase the odds of survival for released animals has been developed and disseminated. Bringing these good practices onto the decks of fishing vessels should contribute to the reduction of the fishing mortality of some vulnerable species. It would be positively viewed by consumers as an act that reduces fishing's footprint on the environment and promoting animal welfare which would improve the image of fishing industry. Mitigation research is by definition an iterative process and different complementary methods must be carried out at different levels of the fishing process to significantly reduce the mortality of the by-catch.
\end{abstract}

\section{Highlights}

A partnership with fishers was developed to integrate their expertise on by-catch issue. Elasmobranchs, an important component of the tropical tuna fishery by-catch, are currently thrown back into the sea. Suitable and non-suitable discarding practices currently occurred within the fleet. - A manual providing the good handling/release practices to the crew was designed. $>$ Other bycatch mitigation opportunities are proposed to be tested. 
Keywords: By-catch ; Tropical purse-seiner ; Sharks ; Handling/release practices ; Mitigation ; Fish welfare

\section{Introduction}

Since the mid-1990s, worldwide tentative assessments of by-catch and discards in fisheries have been attempted [1], [2], [3] and [4] and particular attention has been paid to find solutions to this issue [5] and [6]. In addition to the adoption of the FAO Code of Conduct for Responsible Fisheries [7] and its International Plans of Action (FAO, 1999), which provided a framework to implement the ecosystem approach to fisheries (EAF), market and civil society initiatives emerged. The accidental catching with tropical purse seiners of the charismatic dolphins, has led to profound changes in the fishery business and it appears that public participation is one of the key elements of good governance. In the 1960s, for the first time, the public showed a real interest, attention and indignation to the problem of the mortality of dolphins caught by tropical purse seiners in the Eastern Tropical Pacific [8] and [9]. As a result, the dolphin-associated schools were declared illegal and fishermen could no longer use what was previously the most common and specific method for catching tuna in this part of the Pacific Ocean. Fishermen were forced to change their fishing strategies. Since this inspiring event, the voice of the consumers and citizens on the by-catch issues has been growing [10]. Later, in the 1990s, studies showed that large amounts of cetaceans were caught by "large-scale pelagic drift-net fishing" in international waters [11]. Consequently, in 1992 the UN banned the use of drift nets longer than $2.5 \mathrm{~km}$ long in international waters.

More recently, the tuna-RFMOs (regional fishery management organizations) have made progress by adopting conservation and management measures to mitigate sharks' by-catch in purse seine fisheries (e.g. measures restricting shark finning practices). Nevertheless, Gilman [17] highlighted the fact that none of the tuna RFMOs' shark measures require so far the use of gear technology best practices to reduce incidental sharks catches or have adopted formal biological reference points for elasmobranch stocks or measures to control shark fishing mortality levels that are based on these reference points. 
There has been a global effort by non-governmental organizations (NGO) to promote innovative mitigation measures [12], and by international projects financed by the European Union [13, 14] but also by the stake-holders [15], to investigate new mitigation techniques allowing the reduction of the impacts of tuna fisheries on elasmobranchs.

A variety of mitigation approaches have been proposed to reduce the mortality of elasmobranchs in the major tuna fisheries in general and in the purse seine fisheries in particular [16, 17]. These approaches fall into one of two categories: the modification of the gear or the modification of the fishing strategy. Modification of the gear involves: FADs design and structure [18], installation of an escape panel for sharks in purse seine gear [19] and the deployment of bait station to lure and to attract sharks away from FADs [16], whereas modification of fishing strategy involves: avoidance of "hotspots", restricting setting on FADs and other aggregating objects [20-22] or intentional setting on whale sharks/manta rays and marine mammals [23, 24]. An update of the latest knowledge on by-catch reduction methods has been made available by the Western and Central Pacific Fisheries Commission (WCPFC) (http://bmis.wcpfc.int/index.php, accessed July 2013). Finally, the concept of eco-labelling of seafood, of particular interest to consumers, has lead the fishing industry to consider this issue more carefully $[25,26]$. Therefore, an increasing number of fisheries are applying for a fishery sustainability certification (e.g., SeaChoice and Marine Stewardship Council). The reduction in by-catch levels and implementation of mitigation strategies can be required for the certification conditions [27].

Tuna fisheries are facing increased pressure to decrease the amount of by-catch. The European Tropical tuna purse seiners during their commercial fishing operations often catch incidentally "unwanted fish" (e.g. undersized target fish and unmarketable species). The magnitude of the by-catch of these fleets has been recently estimated per species or group of species in Atlantic [28, 29] and in the Indian Ocean [30]. Though, the annual by-catch of the European tropical tuna purse-seine fishery in the Indian Ocean (mostly observed for FAD sets) over the period 2003-2009 was estimated at $11,590 \mathrm{t}$ [95\% confidence interval: $(8,165-15,818 \mathrm{t})$ ], corresponding to $4.7 \%$ of the tuna landings [30].

Among the species that are accidentally caught by purse seiners, sharks and rays are particularly vulnerable. The life traits of sharks and rays (slow growth rates, late maturation, long gestation, low fecundity and long lives) make them highly susceptible to overfishing, therefore efforts should be made to reduce their mortality [31, 32]. The silky shark (Carcharhinus falciformis) represented more than $65 \%$ of the overall shark group and reached an average value of $8.3 \%$ of the total by-catch biomass [30].

The catch trends suggest that several sharks species have been declining in abundance in recent years [33-36]. This is why many RFMO's and biodiversity conventions have begun to adopt special conservation and management measures for several pelagic shark species and shark groups. RFMOs are requiring vessels to implement special measures to avoid the capture of certain species and to return by-catch alive to the sea. To date, as a little is known of the post-release behavior and potential mortality of elasmobranchs associated with the capture event and the release practices in most of the fisheries worldwide, the effects of this measure are not elucidated. Only one study has been conducted on-board commercial swordfish longline vessels to investigate the fate of blue shark (Prionace glauca) using pop up archival tags while two studies conducted on-board research vessels has documented the post -release survival on the same species using either only Pop up archival tags [37] or the same kind of tags combined with hematological profiling [38]. By applying a risk-based method to semi-quantitatively determine delayed and total post-release survival of three pelagic sharks caught by sharks gillnet [39]. Satellite archival tags were also used to estimate the post-survival of the common thresher shark (Alopias vulpinus) caught in the Californian recreational fishery [40]. The physical and physiological effects of capture stress and post-release survivorship were examined in juvenile sand tigers (Carcharias taurus) angled on conventional rod and reel tackle with offset circle hooks [41] using acoustic tags and haematological profiling. The preliminary results of a study designed to estimate the post-release survival of silky sharks caught incidentally on-board French tropical purse seiners showed that $50 \%$ of the released sharks survived [42].Tropical purse-seine tuna fisheries employ thousands of people and provide a cheap source of proteins. Potential losses of sales 
and market shares are strong incentives. Some shark species are now among the list of charismatic marine animals scrutinized by the public and the environmentalists, and fishers have to adapt their practices if they want to carry on their activities without any complaints from the public. Fishers are businessmen but are also interested in participating in cooperative/collaborative research aimed at improving the sustainability of the fishery [43]. The by-catch issue is well-known to stakeholders and the fishing industry which accept that the problem needed to be addressed.

The research objectives of this study were to identify, for the European purse-seiners fleets, new methods/technologies/strategies and devices to facilitate the release of the elasmobranchs caught incidentally and to reduce the post-release mortality rates. Currently, on-board French vessel, elasmobranchs are thrown back into the sea. This strategy can be an efficient conservation tool as the post-release survival rate is relatively high. The promotion of "good practices" for fishers to handle sharks was in this case justified.

It has been shown that cooperative/collaborative research between fishermen and scientists is important to fisheries management [43-45]. The involvement and the participation of the resource users are also crucial to develop efficient and practical mitigation techniques. Partnerships with commercial fishermen were developed to enable them to participate in this study and to integrate their information, experience and expertise. The first phase of the study was, to describe and document (a) the structure of the vessels (equipment), (b) the fishing strategy and fishing procedures, (c) the conditions faced by sharks and rays at the different phases of the fishing process, (d) the current handling practices. The fishing industry, managed to host scientists on-board during regular commercial purse-seiner cruises in the Atlantic and Indian Oceans. The skippers and crew members allowed scientists to visit the vessels and agreed to reply to the survey and to participate in interviews while in port. The survey and interviews document the perceptions of fishers. A diversity of discarding practices within the fleet was reported, some practices were considered suitable, others needed to be adapted and improved, while others had to be banned, finally. New methods needed to be developed and tested. In light of these observations, it appeared that providing appropriate handling practices to the crew could ensure crew safety and increase the odds of survival for discarded sharks and rays.

The second phase of the study focused on the preparation of a good practices manual to raise increase the fisherse awareness of the preservation and conservation of biodiversity, to increase their knowledge on the biology of sharks and rays, and to encourage their participation in the sustainable management of the marine resources.

Here, the process used to reach this goal is presented and the major solutions proposed in the manual are described. Other by-catch mitigation opportunities to be tested are also proposed.

\section{Material and methods}

\subsection{Trips at sea on-board commercial vessels}

The study was conducted in 2010 and in 2011 on-board commercial French vessels operating in the Atlantic and Indian Oceans during three trips and 71 days of observations.

In the Atlantic Ocean, observations were conducted on-board two French commercial purse-seiners operating off the West African coast $\left(1^{\circ} 15^{\text {ee }} \mathrm{S}-2^{\circ} 57^{e e} \mathrm{~S}\right.$ and $\left.4^{\circ} 25 \mathrm{~W}-12^{\circ} 33 \mathrm{~W}\right)$ during a cruise of 21 days (14 February to 6 March 2010) where 87 tons of tunas were caught in 8 sets but no sharks were observed during this period. Observations in the Indian Ocean were conducted on-board two commercial French purse-seiners operating Western area of the Indian Ocean. During the first cruise of 21 days (16 March to 5 April 2011), 640 tons of tunas were caught during 32 sets. A total of 111 silky sharks (Carcharhinus falciformis) were caught incidentally in 15 sets associated with 503 tons of tunas in the Mozambique Channel. During a second cruise of 31 days (10 May to 9 June 2011), 201 tons of tunas were caught in 15 sets mainly in Mauritius waters (south of Agalega) and in the 
Mozambique Channel. A total of one shortfin mako shark (Isurus oxyrhincus) and 24 silky sharks were observed.

In order to analyse the procedures of the typical fishing operation, variables were routinely recorded on a "shot-by-shot" basis by the scientists including: date, sea surface temperature, fishing type (freeschool, FAD, $\log$ ), set location, shooting time of the net, boat speed, maximum depth reached by the net, end of the setting, beginning and end of the "pursing", beginning and end of the net hauling, beginning and end of the preparation of the bunt, beginning and end of each brailing and total number of brailing and the total amount of tunas loaded. It appeared also crucial (1) to understand when and where the animals were first sighted and to document their behaviour during the capture process, (2) to know where and how the animals were brought on-board and to document how they were handled by the crew. The type and the severity of injuries were also carefully observed.

\subsection{Documentation}

Observations at sea by authors were complemented by investigating observerse pictures database to document a wider range of handling methods and to better identify the potential risks encountered by the elasmobranchs along the different phases of the fishing operation.

\subsection{Interviews and visits to the vessels}

To cover a large number of vessels within the fleet, interviews were conducted at port while purseseiners were landing. The objectives of the interviews were: (1) to track different crews perceptions about the by-catch issue and its magnitude and trends since their activity started; (2) to document the existing mitigation developed on-board (3) to obtain feedback from the crew on proposed by-catch mitigation approaches and on mitigation tools; and (4) to identify other mitigation opportunities. Finally, the visit to the vessels allowed scientists to collect technical information on the equipment on each vessel (brailer, conveyor belt, "waste chute",...).

\subsection{Configuration of gear and vessel}

Visits on-board vessels revealed basic information about the structure of the fleet. The vessels were of different types, sizes and age. Although the fishing techniques were almost identical within the French fleet, notable equipment and workspace on the deck differences among the vessels were found.

Equipment:

\section{Brailer (Scoopnet) and hooper:}

The shape of the hooper is not standard: it can be circular, semi-circular or square. The shape is an important parameter when considering the limited space on a vessel because crews"access to the center of the hopper to sort out unwanted species can sometimes be difficult. The capacity of the brailer is not standard either and varies based on the size of the fish caught. The brailer capacity ranges from 3 to 5 tons for the large tuna and from 5 to 7.5 tons for the small tunas. Tunas are dropped from the brailer directly into the hooper and gradually fall by gravity to the lower deck.

\section{Conveyor belt and Waste chute}

All the vessels visited were equipped in the lower deck with a "conveyor belt" designed to collect and to distribute tunas to the different fish-wells and a "waste chute" to release by-catch to the sea through a hole in the hull. These devices were not standardized; their shape and location varied. Often these devices were either misused or neglected. The conveyor belt is an obstacle to cross for the crew when they want to release sharks that fell on the floor in the middle or at the opposite side of the vessel or when they want to release them from the upper deck. 


\section{Configuration of the deck:}

The general configuration of the deck offers inadequate working space and may reduce access to the fish on one side of the hooper. The location of the crane, used to lift the speed-boat and other goods reduces their effective working radius on the deck. Access to the side rail and door enabling the release of the sharks is also impossible during the fishing operation.

\subsection{Fishing practices}

\section{$\underline{\text { Fishing process }}$}

The fishing operation procedure, already described [46-48], is the same regardless of the structure of each vessel and consists of six routine steps. During the first phase, setting, the vessel encircles the school or the FADs within 4 to 8 minutes. When the school of tuna is inside, the bottom of the net is "pursed" which is the second phase and takes roughly thirty minutes. The third phase net hauling, starts when the net is pulled aboard the purse-seiner with the hydraulic power block. The duration of this phase lasts from 55 to 95 minutes. On the fourth phase, preparation of the bunt, the net is hauled to dry up the catch to make them accessible to the brailer. This phase lasts around 15 minutes. The fifth phase, brailing, consists of the harvesting operation. The duration of this phase depends on the total amount of fish caught but the elapsed time to harvest the fish from the bunt to the deck using the "brailer" is less than 2 minutes. During the following stage, sorting, the sorted tunas go toward the fish-wells. On-board the French vessels, the crew starts sorting the larger by-catch from the hopper in the upper deck and after a short latency period, the fish fall by gravity through the hopper and its funnel to the lower deck where the rest of the by-catch is also put aside. The final phase consists of preparing the fishing gear and the deck to be ready for the next fishing operation (Fig. 1).

-Figure 1

\subsection{Various types of elasmobranchs}

During the fishing process, fishers interact with various types of elasmobranchs that range in size, weight and shape, and pose various degrees of danger to the crew (Table 1). In many cases, by-catch of large elasmobranchs are not easily avoided. The complexity of the handling process increases with the size of the fish. Crew safety is an issue as crewmembers can suffer injuries from either being struck or bitten by large fish and sharks or being stung by stingrays.

TABLE 1

\section{Good handling and release practices manual for elasmobranchs by-caught in tropical tuna purse-seine fisheries}

On-board tropical tuna purse-seiners, "unwanted fish" are sorted and discarded at sea while tunas and other valuable fish are kept on-board. Observations reveal that action is limited to two distinct phases: the brailing and the sorting phases. Removal and release of shark or a ray should occur the moment the animal is removed from the water. However, the release strategy should be planned in advance as actions needed to be taken collectively on-board. It is crucial that each crew member understands their role in the operation. Finally, the "tools" used for releasing must be ready and easily accessible.

Handling animals safely begins with knowing the animales biology and typical behaviour. Some biological traits of sharks and rays make them vulnerable to handling when they are out of water. For example, sharks and rays are very fragile because their internal organs are not protected by a rigid 
skeleton, but held loosely in place by connective tissues. Therefore, more than any other fish, they suffer damage to internal organs when removed from the water because water supports their organs. Out of the water, the connective tissues can easily tear and their organs can be easily crushed because of the weight of the muscular mass on the abdominal organs. Injuries to the spinal cord, ligaments, tendons and internal organs are likely to occur if the animals are lifted by their head or tail. Pressure on the spine can inflict irreversible damage.

Under water, sharks and rays can suffocate if they are restrained because their blood circulation is reduced when they are not moving. Sharks, gills are easily damaged out of the water. Damaged gills prevent breathing properly and may result in a slow death by suffocation. Sensory organs are situated in the snout of the shark: the nostrils (olfaction), the Lorenzini ampullae (electroreceptors), the anterior branches of the lateral line system (detection of movements and vibrations in the surrounding waters) and sensory crypts (chemoreceptors). Shark snouts are very sensitive and fragile. This means that damage to shark snouts can seriously handicap shark by reducing its ability to detect prey. Once caught, fish are first landed on the upper deck from the bunt with the brailer and then sent to the lower deck via the hopper. "Unwanted fish" are manually sorted at both locations. When scientists were onboard, the crew did not treat fish (tuna and "unwanted fish") differently than usual; some rough treatments, inflicting serious damage, were observed.

In the manual "Good practices to reduce the mortality of sharks and rays caught incidentally by tropical tuna purse seiners1" [49], scenarios and handling protocols are presented on a case-by-case basis. The goal of this manual is to recommend the continuation of safe by-catch handling methods, to propose adaptations of other methods and to present new methods to ensure the safe handling of bycatch. The manual provides "Dos" and "Don'ts" to demonstrate good practices for each by-catch category. It was also decided to caution against some of them which were considered dangerous for the crew and/or detrimental for the animals and to propose some guidelines and applicable to the whole fleet.

Handling techniques can be implemented by one person. Small sharks are best handled using both hands: (1) one holding the dorsal fin and the other hand holding the body, or (2) both hands sustaining the body or (3) one hand supporting the pectoral fin and the other hand supporting the tail.

If the boat is equipped with a waste chute in the lower deck, ensure that the water pressure is strong enough to evacuate through the drain pipe.

If the animal is too big for the waste chute or if there is no waste chute on-board, release the animal back to the water as soon as possible using handling technique described above.

Some attitudes and actions must be avoided:

1. Under no circumstances should a shark be lifted by its tail or head alone,

2. Sharks should not be exposed to physical trauma (do not throw it, whatever the distance; do not push it too harshly; and avoid squeezing around the belly, as this can damage the internal organs, etc.),

3. Sharks should not be carried or dragged by inserting your hands in its gill slits,

4. Sharks should not be exposed to the sun.

\subsection{MEDIUM PELAGIC SHARKS}

Medium sized sharks should be handled by two persons: one person to hold the tail while the other person holds the dorsal and pectoral fins, while keeping their body well away from the shark's head. If the release to the water must be delayed, prevent the animal from battering itself on the deck and other hard objects by placing the animal in the shade and watering it regularly. A hose should be placed between the jaws with a moderate flow of water. The shark can be calmed by placing a smooth, wet and dark cloth over its eyes. Biting can be prevented, allowing for safe handling by placing a dead fish (skipjack) or a big stick between its jaws.

\footnotetext{
${ }^{1}$ http://orthongel.fr/index.php?content=cat\&page=requins, accessed July 2013 ; or http://bmis.wcpfc.int/index.php, accessed July 2013
} 
Do not insert a gaff or other pointed objects in the body, jaws or gills to carry or drag the animals, do not expose animals to physical trauma (do not throw it, whatever the distance; do not push it too harshly; and avoid squeezing fish around its belly, as this can damage internal organs, etc.).

\subsection{SMALL AND MEDIUM RAYS}

Small manta ray should be handled by 2 or 3 people and carried by the side of its wings. A ray should not be dragged or carried by its "cephalic lobes". Stingrays should be held away from one se body to avoid lashes of the tail and the contact with the stings.

\subsection{LARGE INDIVIDUALS}

Very large fish, such as large sharks, mantas or moonfish, should be released directly from the brailer. Alternatively, they can be returned to the sea using a piece of net or a canvas sling that is lifted by the crane. Knowing that any fishing operation may include catching large individuals, several tools should be prepared in advance. The crew should store a piece of net (or a canvas sling) to prepare the release of large animals. The use binding wire tightly around the animals' body or inserting wire into their skin in order to tow or lift them is not recommended.

\subsection{WHALE SHARKS}

Many experienced skippers have experience releasing whale sharks from the net and sack without harming them. In some cases, several individuals were caught at the same time, up to height (Captain Allier, Personal communication). This way, they developed non-lethal techniques. The first technique can be used when the whale shark is separated from the tunas and when its head pointed towards the rear of the boat. Either the shark tears the net by the force of its own weight and passes itself or, if the procedure presents no danger, a crewmember can cut a few meters of net in front of the sharke mouth to release it. The second technique can be used when the head whale shark is pointed towards the bow of the boat. The crew in charge of the net hauling operation can maneuver the winch and the capstan to bring the whale shark close to the hull, then stand the animal on the net and to roll it outside the bunt. A rope placed under the animal and attached to the float line could help to roll the whale shark out of the net. Pulling up or towing sharks by the tail is not recommended because of the fragility of the caudal peduncle, the tail can break.

\section{Discussion and conclusions}

\subsection{CONDITIONS FACED BY ELASMOBRANCHS}

Fish that are caught and released, may die for several reasons, but the two primary causes are wounding and stress [50-53]. Sharks and rays face harsh conditions during different phases of the fishing operation and catch processing due to: (1) physical contact with other fish in the bunt and with hard objects surrounding it; (2) the rough harvesting process (in the brail, falling onto the upper and lower decks, entanglement in the net's mesh); (3) removal from the water (lack of oxygen, exposure to the sun and organs crushed because of the weight of gravity) (Fig. 2). Current fishing processes cause injuries with varying degrees of severity from light skin damages in the form of bruises and redness, to external wounds and bleeding or internal organs protruding mostly on the cloaca area. Lifting fish by the tail and mechanically dragging them on the deck and/or towing) induce trauma.

-Figure 2

\subsection{ROLE OF CREW}

Of the 21 French purse-seiners active during the 2011 fishing season, 10 vessels were visited. During the fishing operations, each crew member had a different perspective of by-catch levels due to the narrow speciality focus of their job. Therefore, depending on job duties and location on-board, each crew member had a different about by-catch levels on-board. 
The skipper"s focus of maintaining the vesseles course, corresponding with other vessels and planning for the next set, means that his primary location is on the bridge. He occasionally spends time in the rear of the vessel to monitor the position of the skiff boat which adjust the direction of the vessel against the wind to facilitate the hauling of the bunt.

The crew that uploads fish from the bunt and that operates the brailer must work quickly to ensure that the fish remain clean enough to pass sensitive sanitary tests which ensure a high quality product. They must also work carefully to monitor the hauler and potential equipment failure. The crew must also pay attention to fish entanglement to prevent fish from falling on other crewmembers and to prevent a large animal from interfering with the speed of the loading operation.

The deckhands, crew located on the upper and in the lower decks, have a partial picture of the total quantity of sharks on-board because of their focus on the commercial species.

The mechanic-master, in charge of maintenance and mechanical problems, spends most of his time in the lower deck to monitor all that falls into the holds. Because of his position in the lower deck, he can precisely assess the number of sharks caught during each fishing operation.

\subsection{CREW SAFETY ISSUES}

Fishing is considered to the world's most dangerous occupation. FAO has been working for 30 years on the implementation of the Code of Conduct for Responsible Fisheries with regard to safety at sea in the fisheries sector [54]. Nevertheless, the issue of safety in the fisheries sector with regard to the animal fished has not been raised. Shark and ray handling techniques should be consistently taught and used by everyone. In general, cautious and deliberate movements should be used. Because animal behaviour can be unpredictable, crews should remain on constant alert. Needless hurting animals can make them respond violently. Therefore, fishers should watch for warning signs of animal selfdefense. Some warning signs include a shark flashing its teeth, flopping its tail, battering around or just moving its head. If possible, fishers should avoid handling these animals until they are in a calmer state. If necessary, a shark can be calmed down by covering its eyes with a piece of dark, wet and smooth cloth. A dead fish or big stick can be placed between its jaws to prevent it from biting. Aggressive animals should be noticed to ensure that everyone uses extra caution around them. Practicing good ergonomics, such as keeping ones back straight, can prevent injury when an animal moves suddenly. Helmets, protective footwear and gloves also provide additional safety.

\subsection{HOW TO RAISE FISHERS’ AWARENESS}

Discrepancies between captains ${ }^{\text {ee }}$ observations of the shark by-catch issue on-board and other crew were noticed. This is due to the fact that $73 \%$ of the sharks found were on the lower deck [42] and the part of the crew working on the upper deck, as well as the captain, cannot observe what is happening in the lower deck. This discrepancy explains why the crew considers by-catch to be a minor issue. They do not have an accurate picture of the magnitude of sharks incidentally caught. Moreover, the mean size of the sharks collected in the lower deck was significantly smaller. The small sharks are detected easily in the brailer or in the hopper, by the crew and arrive directly in the lower deck. Thus, the person in charge of the fish wells is best suited to make accurate observations.

Even though large animals provide difficulty to the crew, they are not a favourite topic of discussion. The major area of concern during the Indian Ocean cruises remained the threat of Somali piracy in this ocean, the current tonnage, tonnages of the other vessels, and fish prices.

Releasing sharks and rays at sea is currently a "mitigation measure" adopted on-board the French commercial tropical purse-seiners. Scientists went on-board to report on the effectiveness of this measure. The approach during this study was to observe the current practices, ban some and encourage good ones. There are different discarding practices for by-catch within the same fleet and between fleets. For example, while some crew discard small sharks right away, others discard when they have time, as there is no incentive from the upper deck to do so under current management policies. 
The majority of crews are likely to improve their handling practices only if they are presented with practical suggestions that are not time consuming or difficult to employ. Integrating fishers ${ }^{c e}$ knowledge provided relevant information which has been used to design a guide of good practices dedicated to fishers.

\title{
4.5. OTHER POTENTIAL SOLUTIONS
}

\author{
By-catch "manager"
}

This study has laid the groundwork for future by-catch mitigation research and the foundation for building collaborative relationships to help to solve post-mortality issue. The empowerment of staff could increase the efficacy of this approach. It requires that everyone's duties be clearly defined and that efforts be made to recognize, encourage and reward each crew member for carrying out the duties allocated to him. One deckhand could be designated "By-catch manager" and coordinate good bycatch practices on-board. This would significantly improve the crews ${ }^{\text {ee }}$ awareness of the by-catch issue.

\section{Technical modifications of the deck}

Some modifications of equipment on-board purse-seiners, done through collaboration between fishers, engineers and experts in fishing technology, could facilitate the implementation of some practices and improve the survival of released by-catch. At this stage, some principles and guidelines for further improvements were enumerated and pointed out.

- Waste chutes are useful when they are functional. Therefore, efforts to improve their design and efficiency will increase the rate of survival of the by-catch that passes through them.

- Conveyor belts should be better located and better designed to allow for access to stairways to the upper deck.

- Adjustments of the hopper (size, shape, trap door system) would greatly facilitate the sorting process on the upper deck. Large animals (sharks or rays) could be placed in the hopper with the brailer, isolated from the tunas, pushed out through the hopper trap door and guided back to the sea through a dedicated drain pipe.

- Modification or arrangement of the ship's side rail (on the starboard side ) could facilitate the release of animals back to the sea

- A "capture lasso", item crafted out of an unfinished circle (a U shape) of strings, generally used to catch dogs but modified in purpose not to hurt sharks. It would help to grab and carry large animals safely on a wet and slippery surface (piece of plastic canvas).

Prohibiting the setting in the vicinity of whale sharks

Due to the propensity of tunas to aggregate around large animals, whale sharks can be encircled intentionally or by accident. Whale sharks have a tendency to aggregate on a periodic or seasonal basis at specific sub-tropical and tropical locations around the world [55]. Consequently, more than one animal can be caught during a set, and the same individual, can be caught several times in the season (the rope attached around the tail to release the animal can be recognised easily by the crew). This species is listed in Appendix II of the CITES (Convention for International Trade in Endangered Species of Wild Fauna and Flora) and on Appendix 1 of the United Nations Convention on the Law of the Sea. The whale shark has been assessed as Vulnerable by IUCN (International Union for Conservation of Nature; www.iucnredlist.org.). Whale sharks are legally protected in many countries. In the Pacific Ocean, $12 \%$ of interactions with whale sharks resulted in mortality and approximately 60 individuals died in 2009 [30]. A study using data derived from logbooks systematically filled by captains of the French and Spanish tuna purse seine fleets operating in the Indian and Atlantic Oceans showed that the impact of fishing on the mortality of whale sharks was seemingly lower, only $1 \%$ of the level in the Pacific Ocean [56]. Some RFMOs have discussed adopting measures to prevent their 
use as FADs and to release accidental by-catch unharmed. During the Seventh Regular session of the Western and central Pacific Fisheries Commission (WCPFC) in December 2010, Australia proposed, at the technical and compliance committee, to prohibit the setting of purse seine nets around whale shark and to mitigate the impact of the inadvertent encirclement in developing the best practice guidelines to release whale sharks without injury $[23,24]$. Some captains also admitted that they were reluctant to set on whale sharks considering the problems encountered in the release of these animals. They prefer minimizing nets damages and the time spent to sort out the trapped megafauna.

\section{Combining different mitigation methods}

Releasing by-catch alive in good condition is only a part of the solution. Other mitigation approaches must also be used because significant results will come from a combination of good practices. Not setting on small schools of tuna would considerably reduce by-catch by purse-seiners [20]. Nonentangling FADs would prevent "ghost fishing" [18, 57]. Several research efforts have revealed methods that would avoid encircling sharks [58], or would allow the release of sharks through an escape panel in the net [19]. Preliminary results require further investigation.

\subsection{FUTURE RESEARCH: TRAINING AND POST-IMPLEMENTATION MONITORING}

The simple measures proposed in the guide, based on the findings presented here, require relatively minimal effort by fishermen but could impact substantially and positively the by-catch post-release survival. Like the shark finning awareness issue on-board European vessels forbidden since 1995 on French vessels (but this measure became however fully effective after 2002 when the crew was threatened with penalty in case of non-compliance of this decision), effort should be devoted to promote these practices and to consider the problem of the by-catch as important. It was already noticed that fishermen greatly appreciate seeing the efforts of scientists on-board their fishing vessels to improve the sustainability of their fishery. During the second trip on-board a commercial vessel, scientists discussed with the crew about the possibility of using the crane to lift and release large individuals, e.g. manta rays. One month later, an observer reported on the same vessel that this innovative proposal was already applied on-board to release a large manta ray. Industry would be generally supportive of these measures as they would be easy to implement with relatively little expense.

Communication, education, post-implementation monitoring and long-standing collaboration are the key factors to success of this programme. Transferring the mitigation methods to the entire fleet by training the crew on the practices proposed in the guide, and monitoring the implementation of these practices on-board, are the main focus of the future action.

The discrepancies between the crew regarding their perception of by-catch demonstrate that crew members should be cross-trained because each person has a precise role on-board and could face different situations regarding by-catch. On each vessel, a coordinated teamwork identified in advance, could work routinely in accordance with the chain of procedures proposed in order to be more efficient, to work in safer conditions and to save time.

The handling manual has been distributed to skippers and posters derived from this document provide some information on methods to use and avoid are now displayed on-board vessels. In addition to showing good practices, training workshops has increased fishers" knowledge on the by-catch issue, improved their ability to remain alert and increased their acceptance of these guidelines.

Consistent with the proposed guidance, a "tool kit" has been prepared and will be made available to be tested on-board a number of volunteer vessels. The kits consists of soft rags to cover the eyes of vigorous sharks, two pieces of canvas sling, small $(2 \times 2 \mathrm{~m})$ and medium $(3 \times 3 \mathrm{~m})$, that can be used to lift large individuals by the crane, pairs of strong protection gloves and adapted capture lassos to handle safely large sharks. 
Furthermore, fisherse inputs at the workshops could result in defining other unexplored solutions. Such a method is actually already in place through the initiative of the International Seafood Sustainability Foundation (ISSF, http://iss-foundation.org/, accessed July 2013), which has been conducting workshops between scientists and fishers in all oceans since 2010. This ISSF framework allows for rapidly disseminating findings such as this guide to many fleets for faster implementation and faster exchanges of ideas between skippers and scientists from different fleets and oceans.

The ultimate goal would be an appropriation of the issue by the fishers. Fisher-exchange programs have introduced effective by catch mitigation techniques to other fleets [59]. Some captains report dedicated good practices used for discarding sharks. It appears very important (1) to integrate information, experience, and knowledge of veterans or skippers engaged in the fishery but also (2) to give them the opportunity to share their knowledge acquired in the field to the community. This can only be achieved through international collaboration between fishers, canning industry, management authorities; seafood retailer industry; experts in fishing technology, marine ecology and fisheries scientists and NGOs as conducted by the ISSF as well as the International Fishers Forum (http//www.fishersforum.net initiative, accessed January 2013). Similar research initiatives have been undertaken in the New Zealand tuna purse seine fishery. Skippers and crew are engaged to find effective practical solution to reduce the mortality of protected rays [60]. Reducing the impact of purse seine fishing on pelagic ecosystems is a priority today. Considering the cost of this research and the practices that differ between fleets, it is important to encourage national and international efforts.

\section{Acknowledgements:}

We are grateful to the French skippers and crews who worked voluntarily with the scientists. This study was carried out within the frame of the Contrat Avenir Thonier of the French Producer organisation ORTHONGEL (co-financed by boat-owners, French Ministry of fishing (DPMA) and EU FEP, convention $n^{\circ} 33246 / 2009$ ) and the Commission of the European Communities, specific RTD programme of Framework Programme 7, „Theme 2 - Food, Agriculture, Fisheries and Biotechnology"e, through the research project MADE (Mitigating adverse ecological impacts of open ocean fisheries), contract \#210496. This work does not necessarily reflect the Commission"s views and in no way anticipates its future policy in this area. This work also received support from the International Seafood Sustainabilty Foundation (skippers workshops). We also thank Katherine Ciulla Shook for her editorial comments on this document and the anonymous reviewer and the chief editor for their constructive comments that improved the paper. 


\section{REFERENCES}

[1] Alverson DL, Freeberg MH, Murawski SA, Pope JGA. A global assessment of fisheries bycatch and discards. FAO Fisheries Technical Paper 339 1994:233

[2] FAO. Report of the Technical Consultation to Develop International Guidelines on Bycatch Management and Reduction of Discards. Rome, 6-10 December 2010. Rome, FAO Fisheries and Aquaculture Report. . 2010.

[3] Gillett R. Bycatch in small-scale tuna fisheries: a global study. 2011:116p.

[4] Kelleher K. Discards in the world's marine fisheries, an update. FAO Fisheries Technical Paper No 470 FAO, Rome. 2005:131p.

[5] Campbell LM, Cornwell ML. Human dimensions of bycatch reduction technology: current assumptions and directions for future research. Endangered Species Research. 2008;5:325-34.

[6] Hall MA, Alverson DL, Metuzals KI. By-Catch: Problems and Solutions. Marine Pollution Bulletin. 2000;41:204-19.

[7] FAO. Code of conduct for responsible fisheries.FAO, Rome, Italy. 1995;4.

[8] Perrin WF. The porpoise and the tuna .Sea Frontiers. 14. 1968;3:166-74.

[9] Perrin WF. Using porpoise to catch tuna. World Fishing 1969;18:42-5.

[10] Dobrzynski T, Gray C, Hirshfield M. Oceans at risk: Wasted Catch and the Destruction of Ocean Life. A Report by OCEANA. 2002:30 p.

[11] Perrin WF, Donovan GP, Barlow J. Gillnets and cetaceans.: Reports of the International Whaling Commission. Special Issue 15. 629 pp; 1994.

[12] Bazilchuk N. Smart Gear Competition. Conservation in Practice. 2005;6:96-8.

[13] Dagorn L, Robinson J, Bach P, Deneubourg JL, Moreno G, Di Natale A, et al. MADE: preliminary information on a new EC project to propose measures to mitigate adverse impacts of open ocean fisheries targeting large pelagic fish. ICCAT SCRS/08/060. 2008.

[14] Dagorn L, Poisson F, Seret B, Filmalter J, Moreno G, Cowley P, et al. Mitigating impacts of tropical tuna purse seine fisheries on elasmobranches 2010; ICES Annual Science Conference, Nantes; France, September 2010.

[15] Restrepo V, Dagorn L. International seafood sustainability foundation initiatives to develop and test bycatch mitigation options for tropical purse seine fisheries. In : Thunnus alalunga (ALB) Madrid : ICCAT, 2011, 66 (5), (Collective Volume of Scientific Papers ; 5) 2010: 2026-35.

[16] IATTC. Research on reducing shark bycatch in the tuna purse-seine fishery in the Eastern Tropical Pacific Ocean ,. Working Group on Bycatch, 6th Meeting, 9-10 February 2007, La Jolla, California (USA). 2007; Document BYC-6-06. Inter-American Tropical Tuna Commission. La Jolla, California, USA.:9 p.

[17] Gilman EL. Bycatch governance and best practice mitigation technology in global tuna fisheries. Marine Policy. 2011;35:590-609.

[18] ISSF. ISSF Guide for Non-entangling FADs. International Seafood Sustainability Foundation, McLean, Virginia, USA. 2013.

[19] Itano D, Muir J, Hutchinson M, Leroy B. Development-and-Testing-Release-Panel-Sharks-andNon-target-Finfish-PS. 2012;WCPFC-SC8-2012/EB-WP-14:6 p.

[20] Dagorn L, Filmalter JD, Forget F, Amande MJ, Hall MA, Williams P, et al. Targeting bigger schools can reduce ecosystem impacts of fisheries. Canadian Journal of Fisheries and Aquatic Sciences. 2012;69:1463-7.

[21] Molony B. Estimates of the mortality of non-target species with an initial focus on seabirds, turtles and sharks. 2005.

[22] Bromhead D, J. F, Attard R, Findlay J, Kalish J. A review of the impacts of fish aggregating devices (FADs) on tuna fisheries. In: Final report to the fisheries resources research fund.Canberra $A$, Australia:Bureau of Rural Sciences; 2003., editor.2003. 
[23] Anonymous. Summary Information on Whale Shark and Cetacean Interactions in the Tropical Seventh Regular session 06-10 December 2010, Honolulu, Hawaii, USA. 2010.

[24] Anonymous. Impact of purse seiner fishing activity on whale sharks and cetaceans. WCPFC-TCC72011-DP/01 Technical and compliance committee Seventh Regular Session 28 September - 4 October 2010 Pohnpei, Federated States of Micronesia. 2010.

[25] Ward T, Phillips B. Ecolabelling of Seafood: The Basic Concepts. SEAFOOD Ecolabelling: WileyBlackwell; 2009. p. 1-37.

[26] Kirby DS, Visser C, Hanich Q. Assessment of eco-labelling schemes for Pacific tuna fisheries. Marine Policy. 2013.

[27] MSC. Marine Stewardship Council Fisheries Assessment and Methodology and Guidance to Certification Bodies: Default Assessment Tree, Performance Indicators and Scoring Guideposts. http://www.msc.org. 2008.

[28] Amandè J, Ariz J, Chassot E, Chavance P, Delgado de Molina A, Gaertner D, et al. By-catch and discards of the European purse seine tuna fishery in the Atlantic Ocean : estimation and characteristics for 2008 and 2009 Collect Vol SciPap ICCAT. 2011; 66(5):2113-20

[29] Gaertner D, Ménard F, Carol D, Ariz J, Delgado de Molina A. Bycatch of billfishes by the European tuna purse seine-fishery in the Atlantic Ocean. . Fishery Bulletin 2002;100 (4): p. 683-9.

[30] Amandè MJ, Chassot $E$, Chavance $P$, Murua $H$, de Molina $A D$, Bez N. Precision in bycatch estimates: the case of tuna purse-seine fisheries in the Indian Ocean. ICES Journal of Marine Science: Journal du Conseil. 2012.

[31] Dulvy NK, Baum JK, Clarke S, Compagno LJV, Cortes E, Domingo A, et al. You can swim but you can't hide: the global status and conservation of oceanic pelagic sharks and rays. Aquatic Conservation-Marine and Freshwater Ecosystems. 2008;18:459-82.

[32] Stevens JD, Bonfil R, Dulvy NK, Walker PA. The effects of fishing on sharks, rays, and chimaeras (chondrichthyans), and the implications for marine ecosystems. ICES Journal of Marine Science: Journal du Conseil. 2000;57:476-94.

[33] Myers RA, Worm B. Extinction, survival or recovery of large predatory fishes. Philosophical Transactions of the Royal Society B-Biological Sciences. 2005;360:13-20.

[34] Ferretti F, Myers RA, Serena F, Lotze HK. Loss of large predatory sharks from the Mediterranean Sea. Conservation Biology. 2008;22:952-64.

[35] Baum JK, Myers RA, Kehler DG, Worm B, Harley SJ, Doherty PA. Collapse and conservation of shark populations in the Northwest Atlantic. Science. 2003;299:389-92.

[36] Baum JK, Kehler D, Myers RA. Robust estimates of decline for pelagic shark populations in the northwest Atlantic and Gulf of Mexico. Fisheries. 2005;30:27-30.

[37] Musyl MK, Brill RW, Curran DS, Fragoso NM, McNaughton LM, Nielsen A, et al. Postrelease survival, vertical and horizontal movements, and thermal habitats of five species of pelagic sharks in the central Pacific Ocean. Fishery Bulletin. 2011;109:341-68.

[38] Moyes CD, Fragoso N, Musyl MK, Brill RW. Predicting postrelease survival in large pelagic fish. Transactions of the American Fisheries Society. 2006;135:1389-97.

[39] Braccini M, Van Rijn J, Frick L. High Post-Capture Survival for Sharks, Rays and Chimaeras Discarded in the Main Shark Fishery of Australia? PLoS ONE. 2012;7:e32547.

[40] Heberer C, Aalbers SA, Bernal D, Kohin S, DiFiore B, Sepulveda CA. Insights into catch-andrelease survivorship and stress-induced blood biochemistry of common thresher sharks (Alopias vulpinus) captured in the southern California recreational fishery. Fisheries Research. 2010;106:495500.

[41] Kneebone J, Chisholm J, Bernal D, Skomal G. The physiological effects of capture stress, recovery, and post-release survivorship of juvenile sand tigers (Carcharias taurus) caught on rod and reel. Fisheries Research. 2013;147:103-14.

[42] Poisson F, Vernet AL, Filmalter JD, Goujon M, Dagorn L. Survival rate of silky sharks (Carcharhinus falciformis) caught incidentally onboard French tropical purse seiners. IOTC-2011WPEB07-28. 2011:6. 
[43] Wendt DE, Starr RM. Collaborative Research: An Effective Way to Collect Data for Stock Assessments and Evaluate Marine Protected Areas in California. Mar Coast Fish. 2009;1:315-24.

[44] Carruthers EH, Neis B. Bycatch mitigation in context: Using qualitative interview data to improve assessment and mitigation in a data-rich fishery. Biological Conservation. 2011;144:2289-99.

[45] Hartley TW, Robertson RA. Stakeholder Collaboration in Fisheries Research: Integrating Knowledge Among Fishing Leaders and Science Partners in Northern New England. Soc Natur Resour. 2008;22:42-55.

[46] Dagorn L, Holland KN, Restrepo V, Moreno G. Is it good or bad to fish with FADs? What are the real impacts of the use of drifting FADs on pelagic marine ecosystems? Fish and Fisheries. 2012:DOI: 10.1111/j.467-2979.012.00478.x.

[47] Sacchi J, George JP. Etude de l'optimisation des gréements de senne. Phase 1. Analyse fonctionnelle. Gréments et manoeuvres des thoniers français. Contrat Ministère de I'Industrie/IFREMER 90/ 1211157/BF. 1990:35 p.

[48] Ben-Yami M. Purse seining manual: FAO and Fishing News Books Ltd. ; 1994

[49] Poisson F, Séret B, Vernet AL, Goujon M, Dagorn L. Good practices to reduce the mortality of sharks and rays caught incidentally by the tropical tuna purse seiners. Mitigating impacts of fishing on pelagic ecosystems: towards ecosystem-based management of tuna fisheries 15-18 October 2012 Aquarium Mare Nostrum, Montpellier, France. 2012.

[50] Brooks EJ, Mandelman JW, Sloman KA, Liss S, Danylchuk AJ, Cooke SJ, et al. The physiological response of the Caribbean reef shark (Carcharhinus perezi) to longline capture. Comparative Biochemistry and Physiology a-Molecular \& Integrative Physiology. 2012;162:94-100.

[51] Campana SE, Joyce W, Manning M. Bycatch and discard mortality in commercially caught blue sharks Prionace glauca assessed using archival satellite pop-up tags. . Mar Ecol Prog Ser. 2009;387 241-53.

[52] Mandelman J, Skomal G. Differential sensitivity to capture stress assessed by blood acid-base status in five carcharhinid sharks. J Comp Physiol B. 2009;179:267-77.

[53] Morgan A, Burgess GH. At-vessel fishing mortality for six species of sharks caught in the Northwest Atlantic and Gulf of Mexico. Gulf Caribb Res. 2007;19 (2):1-7.

[54] FAO. Report of the Expert Consultation on Best Practices for Safety at Sea in the Fisheries Sector. 2008:Rome, FAO. 2009. 40p.

[55] Stevens JD. Whale shark (Rhincodon typus) biology and ecology: A review of the primary literature. Fisheries Research. 2007;84:4-9.

[56] Capietto A, Pianet R, Delgado de Molina A, Murua H, Floch L, Damiano A, et al. Interactions between whale sharks and the European tropical tuna purse seine fishery in the Indian and Atlantic Oceans. 2012.

[57] Dagorn L, Filmalter J, F. F. Summary of results on the development of methods to reduce the mortality of silky sharks by purse seiners. . 2012;Eighth Working Party on Ecosystems and Bycatch ,Cape Town, South Africa, 17 - 19 September 2012.

[58] Dagorn J, Filmalter J, Forget F. Summary of results on the development of methods to reduce themortality of silky sharks by purse seiners. IOTC-2012-WPEB08-21. 2012.

[59] Hall SJ, Mainprize BM. Managing by-catch and discards: how much progress are we making and how can we do better? Fish and Fisheries. 2005;6:134-55.

[60] Jones $\mathrm{E}$, Francis $\mathrm{M}$. Protected rays - occurrence and development of mitigation methods in the New Zealand tuna purse seine fishery. 2012:37 p. 
Graphical Abstract (for review)

\section{Figure captions}

Figure 1: Timing for the common phases of the fishing process

Figure 2: Conditions which reduce the chance of survival of by-catch during different phases of the fishing process on-board a tropical tuna purse-seiner,

Table 1 : Categories of elasmobranchs captured by purse-seiners and corresponding risk for the crew. 
Click here to download high resolution image

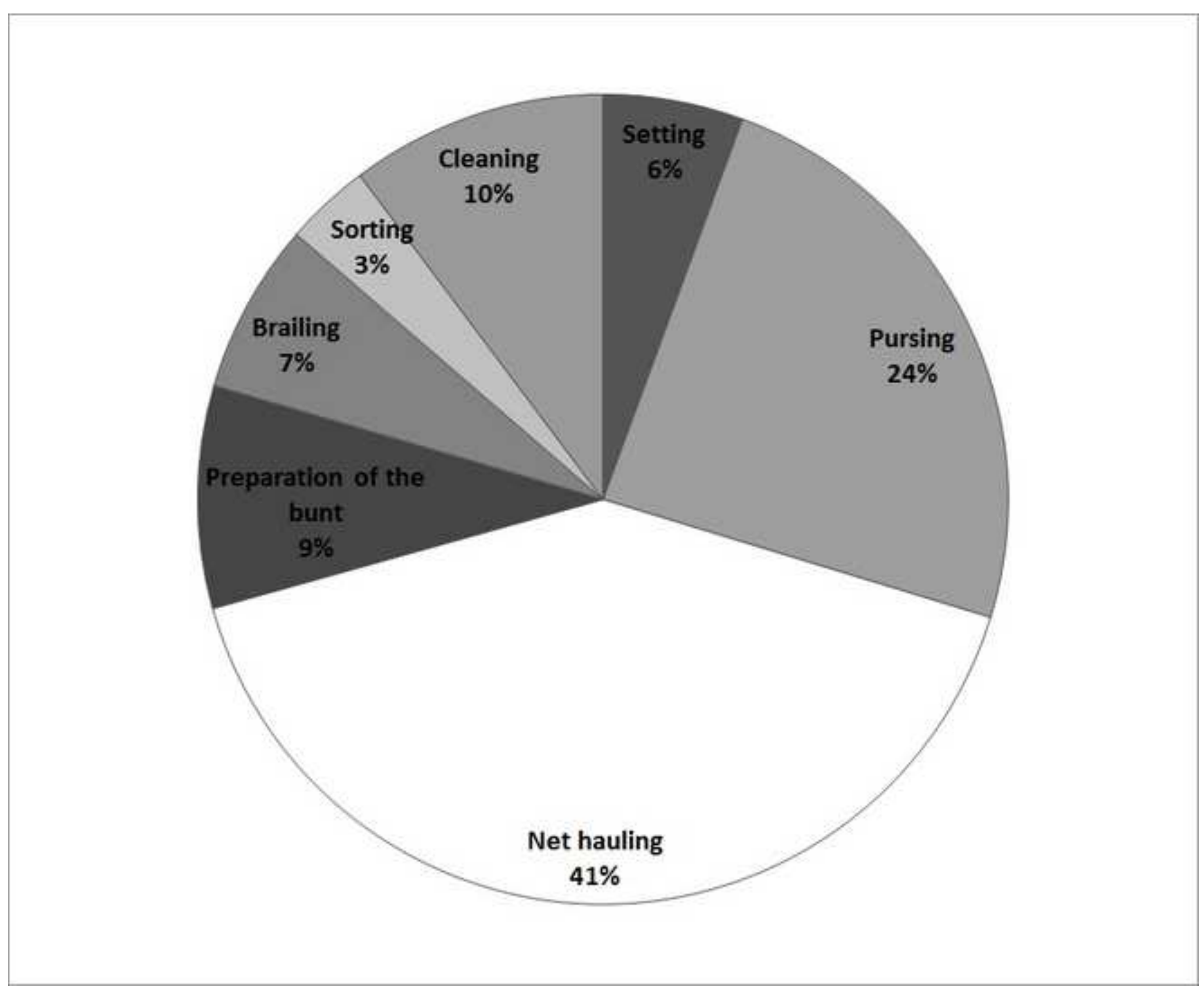


Click here to download high resolution image

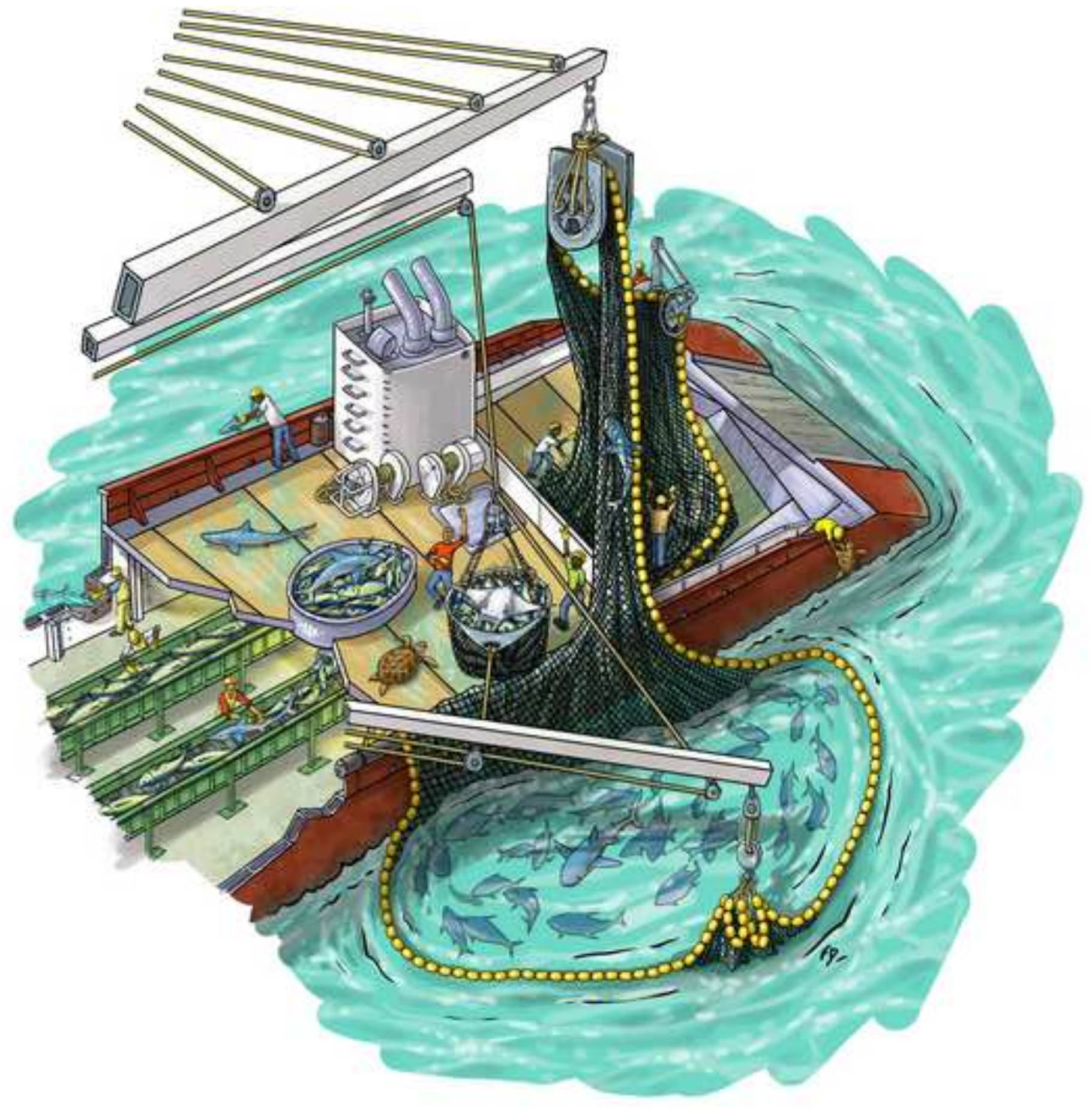




\begin{tabular}{lllll}
\hline Categories & Weight & Length & Width & Risk to the crew \\
\hline Large whale sharks & $300-3000 \mathrm{~kg}$ & $4-9 \mathrm{~m}$ & - & Blows \\
Medium whale sharks & $100-300 \mathrm{~kg}$ & $3-4 \mathrm{~m}$ & - & Blows \\
Large rays & $>70 \mathrm{~kg}$ & - & $>2 \mathrm{~m}$ & None \\
Medium rays & $30-70 \mathrm{~kg}$ & - & $<2 \mathrm{~m}$ & None \\
Small rays (stingray) & $<30 \mathrm{~kg}$ & - & - & Sting \\
Medium/Large sharks & $>10 \mathrm{~kg}$ & $>0.8 \mathrm{~m}$ & - & Sharks bites, blows \\
Small sharks & $<10 \mathrm{~kg}$ & $<0.8 \mathrm{~m}$ & - & Sharks bites, blows \\
\hline
\end{tabular}

Table 1 : Categories of elasmobranchs captured by purse-seiners and corresponding risk for the crew. 